\title{
PANEM. SOBRE SEU VIÉS DE GÊNERO ENTRE OS ZO'É*
}

\author{
Leonardo Viana Braga ${ }^{1}$
}

${ }^{1}$ Universidade de São Paulo, São Paulo, SP, Brasil

A noção de panema, palavra de origem tupi (cf. Galvão 1951:222; DaMatta 1967:05), é conhecida desde o início do período colonial, estando presente nas obras dos cronistas dessa época (cf. Montoya 2011 [1639]:364365; Fernandes 1963 [1949]:298; 2006 [1952]:257, 545). Seus significados mais conhecidos são o de "azar", "má sorte" e "infelicidade". Remete aos contextos do insucesso na pesca, nas interações com os vegetais, nas relações conjugais e na caçada. Em pesquisa etnográfica realizada com os Zo'é1 (cf. Braga 2017), busquei contribuir com o entendimento de panema no decurso de reflexões feitas por eles em torno do fato de não matar caça. De início, levei em consideração a atenção de Roberto DaMatta (1967:7) à sua causalidade múltipla. Sabe-se que não se trata de um sistema causal simples e/ou uma "simples relação de causa e efeito que conecta presa e predador" (Almeida 2013:15). Além disso, sabemos que ela envolve, normalmente, descuidos e excessos por parte das pessoas e/ou ações intencionais de outrem - o que faz de panema muitas vezes um assunto delicado. ${ }^{2}$

Nesse sentido, procurei dialogar com algumas propostas teóricas e com materiais etnográficos produzidos pela etnologia indígena nas últimas décadas (cf. Viveiros de Castro 1996; T. S. Lima 1996, 2011; Descola 2001 [1996]), inclusive monografias consistentes sobre o tema da caçada (ver, por exemplo, Descola 2006 [1993]; Garcia 2010). Apontei que, também entre os Zo'é, a busca pelo sucesso no abate de um animal exige um confronto com a agência deste, realizada por meio de diversos procedimentos corporais, morais e intelectuais. Em consonância com trabalhos de referência (Kwon 1998; Descola 2006 [1993]; Garcia 2010, 2012; Willerslev 2012), defendi que os sentidos da caçada não podem ser apreendidos apenas realizando-se uma descrição minuciosa do que acontece na floresta, na iminência de um abate. 
É necessário realizar uma verdadeira etnografia dos bastidores da caçada para se atingirem esses contextos.

Dessa feita, para além de um simples azar - ou do azar como uma explicação simples -, propus que, enquanto uma situação de "luta" (T. S. Lima 1996: 37-38) entre o caçador e a caça, ter panem, tal como dito pelos Zo'é, "designa uma relação" (cf. Almeida 2013:14). E, ainda, que essa relação entre caçador e caça correlaciona outras relações, tais como: entre um homem e a carne de caça enquanto um alimento; entre um homem e aqueles com os quais convive; entre kubi'e e kujã , respectivamente, "homem" e "mulher".

Neste artigo, por sua vez, proponho seguir o itinerário etnográfico declarado por Claude Lévi-Strauss logo no primeiro parágrafo das Mitológicas:

O objetivo deste livro é mostrar de que modo categorias empíricas, como as de cru e de cozido, de fresco e de podre, de molhado e de queimado etc., definíveis com precisão pela mera observação etnográfica, e sempre a partir do ponto de vista de uma cultura particular, podem servir como ferramentas conceituais para isolar noções abstratas e encadeá-las em proposições (Lévi-Strauss 2004 [1964]:19).

Como veremos, panem está em relação direta com uma "lógica das qualidades sensíveis" (Lévi-Strauss 2008 [1962]; 2003 [1964]:19, 280; 2005 [1967]:444-445; 2006 [1968]:422-423, 459), uma vez que o corpo panem é descrito por meio de categorias que orbitam em torno de aspectos olfativos. No primeiro momento do texto, demonstrarei como elas conectam diferentes âmbitos, tais como a culinária, os resguardos e a caçada. Será destacada a importância da moderação como uma potência para o sucesso no abate, ressaltando-se que abster-se de caçar durante períodos de resguardo não designa panem. Em um segundo momento, veremos como o gênero pode contribuir para o entendimento de panem. O insucesso na caçada permite que homens que existem enquanto panem sejam comparados com as mulheres. Em se tratando de não matar caça, mostrarei que o corpo panem é uma exclusividade dos homens em detrimento das mulheres.

Por fim, partindo do entendimento de como essas categorias olfativas funcionam no âmbito de panem, apontarei que é possível isolar conceitos como os de corpo, pessoa, desejo e, principalmente, relação. E, assim, proponho que a perspectiva de gênero combinada à atenção a diferentes casos de homens panem permite relativizar uma possível negatividade da existência dos mesmos, argumentando que sua vida não se reduz a tal condição. 


\section{Panem e a lógica das qualidades sensíveis}

Da perspectiva dos Zo'é, o afastamento entre o caçador e a caça é caracterizado como uma questão olfativa: ${ }^{3}$ panem ika a'e tepot nem, se "tem panema, então [o] corpo da pessoa fede", o que permite que a caça o perceba e fuja. A categoria nem, "podre", "fétido", faz parte de uma classificação de cheiros que abarca a caracterização dos animais, dos vegetais e dos alimentos, por exemplo. São elas: nem, ikasing, pisi'u e piji. O nem é cheiro de carniça. Cheiro de restos de comida. É cheiro de determinadas carnes não desejadas, como, por exemplo, a de cobras, lagartos e de onça-parda (Felis concolor). É também um cheiro marcante de outras presenças. É atribuído aos espectros terrestres. Indica a proximidade de inimigos e de monstros terrestres altamente maléficos, como a onça-de-duas-cabeças e a cobra-tucano.

Um primeiro sentido de ikasing é a própria tradução da palavra "cheiro". Por isso ele pode ser qualificado de maneira mais abstrata, com em ikasing katu, "cheiro bom", ikasing he, "cheiro gostoso", ou ikasing dahej, "cheiro não gostoso". Ou então combinando-se com outras noções para singularizar, por exemplo, quando se diz que lagartos têm ikasing nem, "cheiro podre". Mesmo parecendo ser um termo geral, sempre que se pergunta o que é que tem ikasing, a resposta é quase unânime e específica: a queixada (Tayassu pecari) e o caititu (Pecari tajacu). E logo em seguida fazem referência ao cheiro exalado pela glândula odorífera que estes animais possuem. Nesse sentido, ikasing pode ser entendido também como um "odor forte".

O pisi'u é a palavra cognata de mais uma categoria tupi que deu origem a um termo muito popular na Amazônia: o "pitiú". Nas cidades, designa um cheiro forte, cujo exemplo emblemático é o fedor de peixe cru ou podre. Para os Zo'é, o pisi'u caracteriza uma ligação direta com a carne kowe, "crua", ou, mais precisamente, com a presença de wy, "sangue"; toda carne, enquanto não for lavada e bem cozida, tem pisi'u. Arriscaria dizer que pisi'u é um cheiro com componente visual, no sentido de que sempre exige uma averiguação da presença de sangue pelo olhar, observado durante o preparo ou na hora do consumo. A presença de sangue também caracteriza as mulheres menstruadas como tendo pisi'u. Como em tantos outros casos (para uma síntese, ver Belaunde 2006), para os Zo'é, o sangue menstrual é extremamente perigoso. A menstruação pode atrair agentes patogênicos que se enraivecem com o cheiro de sangue e se vingam da mulher menstruada e daqueles com os quais ela pode compartilhar seu cheiro. Sendo "a administração do [fluxo de sangue] crucial para ambos os gêneros" (:206), destaca-se que o contato com o sangue menstrual é uma das principais causas de panem. 
O piji, por sua vez, pode ser traduzido como "aromático". Ao mesmo tempo em que indica algo cheiroso, "aromático" também expressa algo perigoso porque atraente demais. Alguns alimentos que passam pelo fogo exalam piji e são muito desejados pelos Zo'é. É o caso dos derivados de mandioca-brava (Manihot esculenta), como a farinha, o beiju e a tapioca, e principalmente das carnes moqueadas - destacando-se que não se consomem carnes assim processadas sem que antes sejam fervidas, justamente pela dúvida quanto à eliminação de todo o sangue. Os corpos de todos os Zo'é exalam piji. Eles não sentem o piji uns dos outros, mas vários predadores, agressores ou captores sentem, como, por exemplo, alguns cultivares e animais. Mas não sentem o de qualquer pessoa e em qualquer momento. Suas reações agressivas ao piji são predominantemente contra grávidas, recém-nascidos, crianças pequenas, puérperas, pessoas doentes e/ou moribundas e homens adultos em resguardo. Essas pessoas manifestam um piji mais intenso do que o comum. E, com isso, aqueles com os quais convivem também se tornam mais vulneráveis, uma vez que o piji é compartilhado mais fortemente com pessoas mais próximas (cf. Havt 2001:10, 73, 128, 132). Tal como no caso das mulheres menstruadas, citado acima, essas pessoas devem manter uma postura moderada: recém-nascidos não podem chorar demais; crianças não podem brincar demais; parturientes, puérperas, doentes, homens adultos em resguardo não devem praticar certas atividades ou mesmo andar demais, evitando riscos para si e para os outros.

\section{Ponto de faro}

Entre os Zo'é, eu destacaria quatro âmbitos nos quais se usa concretamente o termo panem: na caçada, nas relações conjugais, na pesca, no cultivo e no roçado. Tal como os animais, as plantas e os peixes sabem -etun, "cheirar", sabem -napyj, "farejar". Os cultivares podem ser qualificados como panem quando reagem à aproximação dos Zo'é. Durante os processos de maturação e frutificação, eles exigem que cultivadores não se aproximem, dado o seu piji. Isto se agrava no caso de pessoas que estejam exalando piji em excesso, como nas situações enumeradas acima. Os cultivares deixam de dar fruto e/ou morrem, sendo assim qualificados como panem. Quanto à pesca, o pescador tem panem caso os peixes sintam seu piji, e não mordam a isca.

Em relação à vida conjugal, conheci a história de um homem já falecido qualificado como panem por não conseguir esposas, uma vez que era estrábico, muito feio e tinha o corpo nem às narinas de outros Zo'é - a 
perspectiva zo'é aqui é importante, como será visto à frente. Ele é sempre lembrado como o exemplo paradigmático do solteiro. Em outra situação, temos uma jovem atualmente com 19 anos e que apenas se casou há dois. Ainda que outras mulheres tenham se casado mais velhas, ela é tomada como exemplo de mulher panem por ter demorado a ter um esposo, um jovem de seu subgrupo. Nota-se que ela era bastante cobiçada por homens de outros grupos, um deles um dos mais importantes líderes zo'é da atualidade. Além disso, mulheres bem mais maduras e há muito casadas tomam-na de exemplo para se compararem, demonstrando um viés positivo no fato de terem elas mesmas sido bastante namoradeiras e demorado para se casarem.

$\mathrm{Na}$ qualidade de cheiro marcante, o piji tanto atrai quanto afasta. Contrastemos situações de caçada. Entre os Zo'é, repete-se o exemplo sobre o embate com as queixadas, que foi chave para a explicitação da teoria perspectivista (T. S. Lima 1996:37; cf. também Garcia 2012:33-34). Se os Zo'é entendem a matança de queixadas como caçada, para estas o intuito é fazer do caçador um cativo, um potencial esposo para sua mãe. Diz-se das queixadas que têm sucesso que elas têm -ihy, "agressividade" suficiente para capturar o caçador. Homens que foram capturados relatam que lá longe, na morada subterrânea das queixadas, tudo é como uma aldeia zo'é: tem roça, tem casa, tem flechas zo'é que foram roubadas em outras situações de caçada e que ficam guardadas nos jiraus da casa. As pessoas são belas, incluindo a pretendente, que recebe o caçador com todas as mordomias, principalmente alimentando-o bem. Por outro lado, seus filhos, guerreiros agressivos, mesmo tendo-o trazido a pedido da mãe, não se conformam com sua presença ali. Ao perceber isso, em dado momento, o caçador resolve fugir e voltar para sua própria casa. Essa precaução é explicada por meio do piji. Dizem que ele não tinha piji uhu, "aroma grande", forte o suficiente para aceitar aquela nova vida, diferentemente de outros caçadores que nunca voltaram. A fuga do caçador é vista como uma atitude moderada diante de uma situação arriscada por ser tão sedutora.

O piji também atua no caso de panem. Se, como foi visto acima, o corpo da pessoa panem é nem, "fétido", ele também é marcadamente aromático. Quando o caçador tem piji, ele é facilmente percebido por animais que possuem bom faro, como veados e porcos. O corpo do caçador panem é tão fétido que nem mesmo as onças vêm até ele. Mesmo animais que não têm faro muito apurado conseguem sentir seu cheiro forte, tal como cotias (Dasyprocta sp.), pacas (Cuniculus sp.) e mutuns (Mitu sp.), que percebem a presença do caçador ainda que ele esteja escondido em uma espera - tocaia ou mutá. É dito que esses animais têm -paje, capacidade de reação, manifestada por sua esquiva. É por isso que caçadores precisam 
sempre cuidar do cheiro de seu corpo. Seguindo à risca a recomendação de tomar banho com a entrecasca de sibo'y, especialmente nas situações extremas de resguardo, ele precisa investir em sua capacidade de passar despercebido pela caça, e, concomitantemente, zelar pela vida dos outros, como demonstrarei melhor à frente.

O corpo fétido não é algo exclusivo de um caçador. Aqueles que são experimentados conhecem bem os cheiros dos animais. Diz-se que reconhecem facilmente o fedor de uma onça ou de uma cobra. E, dessa forma, induzir a relação panem também pode ser usado como forma de defesa contra esses predadores. Os Zo'é realizam -peju, um soprar seguido de um falar eficaz, para afastar esses animais e/ou para que eles possam ser percebidos na floresta (para uma comparação, ver, por exemplo, Viveiros de Castro 1986:267, 540; Gallois 1988:298-299). Usando um instrumento feito da carapaça de um caramujo, a -hy, "mãe" - ou uma -ridyt, "irmã" do caçador em potencial vai batendo levemente na moleira do seu filho e entoando frases como: arakuku pyta paneeeem, "surucucu [Lachesis sp.] fique paneeema"; jaware'e paneroheeem, "onça-pintada [Panthera onca] veeenha panema". Essas ações são chamadas boj panem e jawara panem, respectivamente, "cobra panema" e "onça panema". ${ }^{4}$

Esses exemplos nos fazem entender que o piji é apreendido de acordo com os pontos de vista em jogo. Dependendo da perspectiva, o cheiro atrai ou afasta. O recém-nascido que exala piji atrai uma onça predadora, enquanto o piji do caçador - que pode estar com seu cheiro intensificado justamente por causa da existência de seu filho recém-nascido - é tomado pela onça com repulsa, negando-se a predar o corpo de um homem panem. O piji se caracteriza, portanto, por sua ambivalência, pois contém em si tanto a atração quanto a repulsa (para uma comparação, cf. Gallois 1988:205), tanto o "desejo" (Gow 1989, tradução própria) quanto o "insulto" (Almeida 2013:15). Assim como já apontou Nadja Havt (2001:143), a categoria piji é base do entendimento sobre panem e, eu diria, de praticamente todos os contextos em que opera uma lógica das qualidades sensíveis entre os Zo'é. Ela é uma categoria central dentro do quadro de relações "multinaturalistas" (Viveiros de Castro 1996:120) vividas por eles, o que me permite afirmar que eles enfatizam um ponto de faro, e não um "ponto de vista" (:115; cf. também T. S. Lima 1996:21), em suas relações com o natural e o cultural. Dito de outra forma, algo como um perspectivismo olfativo. ${ }^{5}$ 


\section{Matar: uma questão de desejo}

No final de $A$ origem dos modos à mesa, Lévi-Strauss aproxima a culinária dos resguardos realizados pelas jovens púberes, afirmando que "regimes alimentares, bons modos, talheres e utensílios de higiene, todos [são] meios da mediação" (2006 [1968]:459). Esses meios podem ser pensados de maneira análoga, uma vez que "consistem a um só tempo numa ação sobre o mundo natural - sobre a caça, a pesca e as plantas cultivadas - e sobre as pessoas, os sujeitos" (Sztutman 2009:302), decorrendo disso significados éticos e morais para os povos ameríndios. Como vimos acima, o piji pode ser entendido como uma categoria que explica diferentes situações de mediação. O processo de cocção, os banhos de sibo'y, o soprar-falar eficaz contra cobras e onças conectam natureza e cultura, e nos permitem aproximar diferentes relações vividas por um caçador, logo, por um homem potencialmente panem.

Segundo DaMatta (1967:09), as causas de panema estão sempre direta ou indiretamente ligadas à alimentação. Alimentação e caçada são interligadas por motivos óbvios. Entretanto, podemos aproximá-las também por uma via já muito conhecida na etnologia: sua relação com a guerra (ver, por exemplo, Fernandes 2003 [1952]:58-63; Gallois 1988:213-215; T. S. Lima 1996:37; Garcia 2010:329). Para os Zo'é, a caçada envolve dois tipos de desejos imbricados entre si: -'urahy, "querer comer", e -jukerahy, "querer matar". A noção de bijet pode ser traduzida como "caça", uma vez que define "a carne que se come". Todo animal tem -pot, "conteúdo", "carne", mas nem toda -pot é desejável. A carne de guariba (Alouatta sp.) é lembrada como a mais cheirosa. Cobras, lagartos e onça parda são nem e, por isso, não comidas; elas não são bijet. No consumo de carnes, querer comer pode ser avaliado pelas qualidades sensíveis das mesmas: pelos sabores, se he ou dahej, "gostosa" ou "não gostosa"; pela consistência, se py ou dipyj, "mole" ou "não mole"; tarak ou dataragi, "dura" ou "não dura"; pelos seus aspectos visuais, se sing ou byk, "clara" ou "escura"; pelo tamanho, se hohoj ou dahohoj, "larga" ou "não larga"; uhu ou tik, "grande" ou "pequena"; pela presença ou não de gordura, ike ou dikej, "gorda" ou "não gorda", sendo as carnes não duras, claras, grandes e gordurosas as mais apreciadas. Mas é o mau cheiro, nem, que caracteriza sua evitação por excelência, e o piji enquanto cheiro aromático que qualifica as carnes mais desejadas.

Porém, a combinação das qualidades das carnes permite relativizar preferências e, até mesmo, permite o consumo de carnes normalmente não comidas. A presença de muita gordura pode levar a -ãrahy, "querer experimentar" uma carne tida como nem, como é o caso da carne de jiboia 
(Boa sp.), desencadeando o consumo de uma carne não classificada como bijet. A onça pintada é considerada bijet, ainda que não se vá à floresta com o intuito de caçá-la e que sua carne seja tarak, "dura" e nem a'u, "consideravelmente fétida". Diz-se que é uma caça hohoj, "grande", desejada pela fartura. Contudo, jamais se deverá matar e, ainda menos, consumir a carne de uma onça quando se estiver em resguardo.

Querer comer também pode ser expresso por alguns dos principais bons modos à mesa. Nesse âmbito, duas etiquetas são sempre destacadas pelos Zo'é: -'u pori, "comer junto", e do'uhuj, "não comer muito". Comer junto envolve não só ter o suficiente, mas sobretudo saber distribuir comida para todos, não ser sovina e dedicar os pedaços corretos para as pessoas certas. A sovinice se articula diretamente com a glutonaria. "Comer demais", -'u uhu, pode ser uma das causas de dijewori, "não disposição". Diferentemente de outros casos (ver, por exemplo, Gallois 1988:208-209), a sovinice e a glutonaria por si sós não são causas de panem. Mas, muitas vezes, são indicadas como evidência da falta de iniciativa de alguns jovens em ir caçar e do desprestígio de alguns caçadores experientes. As qualidades das caças correlacionam a glutonaria com diferenças de maturação e gênero. Meninos e meninas pequenos têm mais aval para comer demais, imoderadamente, sendo comum se retirar comida de um adulto para dar à criança que deseja repetir. Às crianças são restringidas determinadas partes da caça, como a cabeça do coatá (Atelles sp.) e do guariba, pois o consumo por uma criança pode transferir as características do animal a ela, que ficará com a cabeça grande; uma mulher que já passou pelo climatério pode comer livremente partes das vísceras que, por serem muito sangrentas, antes lhe eram vetadas, para que não potencializassem o fluxo menstrual. Por sua vez, aos meninos pequenos - mais ou menos de 2 anos de idade -, diferentemente de meninas de mesmo tamanho, não é indicado o consumo de coatá e guariba, para evitar que tenham panem especificamente com esses animais no futuro.

Desde a primeira infância, portanto, preocupa-se com -jukerahy, "querer matar". Ao longo da vida de um potencial caçador, é feita uma série de procedimentos sobre seu corpo, seja ele um neófito ou um homem já experimentado. Homens panem podem tentar incorporar as habilidades do gavião-real (Harpia harpyja), por exemplo. Partes do corpo desse animal, abatido anteriormente por um bom caçador, podem ser usadas em dois procedimentos: uma amute, mulher casável, aplica um colírio feito com o sumo do olho daquele animal para que o caçador oesagatu, "ele enxergue bem" a caça no momento do abate; e abre-se um corte na parte frontal do ombro, onde será colocada uma garra do animal, que permanecerá dentro da carne do rapaz após a cicatrização e, assim, fará o jovem boereahu, 
(bo- = indica transformação [de perspectiva] + ereahu = "gavião-real"), "transformar-se em gavião-real". Este segundo procedimento é conduzido por um caçador experiente, considerado ereahu ate, "gavião-real mesmo", que não pode ser nem seu(s) -tu, "pai(s)", nem seu(s) - $a m u$, "irmão(s)". Trata-se de evitar panem e, concomitantemente, produzir um corpo caçador específico, uma vez que o gavião-real é o principal predador de macacos e preguiças, mas não de caças terrestres.

Por fim, existem procedimentos éticos exercitados cotidianamente no âmbito da caçada. Assim como acontece com outros povos ameríndios (ver, por exemplo, Descola 2006 [1993]:154), evita-se enunciar a saída para caçar, principalmente especificando-se a espécie de caça que se pretende abater, pois ela pode fugir de antemão. Não matar demais em uma caçada é uma precaução necessária para evitar panem com outros animais da mesma espécie e até mesmo suas agressões. Esta ética se soma, portanto, às características do corpo e às intervenções sobre ele para que o caçador possa enganar a(s) caça(s). É preciso -ho nimim, "ir escondido", "passar despercebido", algo que o silêncio e a invisibilidade, por si sós, não parecem garantir.

\section{Moderação: uma questão de estratégia}

Entre os Zo'é, os dados apresentam uma variação etnográfica do famoso resguardo do matador tupi (cf. Fernandes 2006 [1952]; Viveiros de Castro 1986; Gallois 1988; Garcia 2010). Toda vez que um caçador mata uma espécie de caça pela primeira vez, ele é submetido a procedimentos determinados. Quando se trata de anta (Tapirus terrestris), por exemplo, essas ações são bastante elaboradas (cf. Havt 2001:137). O matador passará por escarificações feitas por um caçador experiente com quem convive, provavelmente seu -tu, "pai", e/ou uma de suas -ridyt, "irmãs". Elas são feitas nas panturrilhas e nos braços, para que se elimine a atã atã , artralgia, e a dijewori, "não disposição" pela qual foi acometido por causa do abate. Seu corpo está impregnado de piji, o estigma da vulnerabilidade que o toma e que contagia as pessoas que convivem com ele. Por isso, uma mulher o banha ao -panun, "esfregar" as fibras de sibo'y em seu corpo; necessariamente deve ser uma amute, mulher casável para evitar panem. Em seguida, ele entra em resguardo. Por cerca de duas a três noites, ele ficará recluso dentro de uma tocaia feita no canto de sua casa.

Assim que ele se reclui, inicia-se o banquete. A carne da anta será entregue preferencialmente ao pai do jovem, que, com isso, é chamado tapi'irapora ijet, "dono da carne da anta", e se torna responsável por sua 
distribuição. O caçador nunca comerá dessa carne, algo que se estende para aqueles com os quais convive - no caso de todas as caças maiores - pois isso seria causa de panem com anta. O mesmo acontece se homens e mulheres não comerem a carne em espaços e momentos diferentes no primeiro repasto. Enquanto está recluso, o matador ficará em sua rede, com as mãos amarradas, cabeça deitada no ombro, falando só o necessário, levantando-se para fazer seu asseio. Visando atrair outras antas, sentado ao lado de quem come, ele também sai da tocaia para pegar o rabo do animal e -panun, "esfregá-lo" em seus dedos das mãos e dos pés para desenvolver destreza para um novo abate. Esse procedimento é acompanhado de -'ã, "imitar" o som emitido pelo animal, e de um peju, "soprar-falar eficaz" feito por ele próprio, dentre os quais pode-se destacar a seguinte frase: eawuihe ika mo'e, tapiok ta'u tapi'irekeeee!, "por causa da minha fala enfática existe caça, para eu comer tapioca [vou] obter aaaaanta!".

As vísceras do animal também podem ser -panun, "esfregadas" em seus dedos, por sua -hy, "mãe" e/ou irmãs, e, ainda, nas pernas, para owata puku, "ele andar comprido" - distante e bastante. Durante o período omuha tenana, "ele apenas [vai] pensar", "apenas se concentrar". Vai se abster de sexo, evitar andar demais, ir à floresta e principalmente matar caça. Não se resguardar despertará a vingança imediata das caças, que certamente irão agredir alguém que tenha piji em excesso, gerando dores e podendo levar à morte. No final da reclusão, ele outra vez tomará banho com sibo'y e será pintado com urucum, cujo ikasing, "cheiro", espantará as agressões, findando o resguardo. Feitos todos esses procedimentos e seguindo-se as posturas indicadas, é dito do jovem estreante que ojuke potat jiapyt (o- = prefixo de terceira pessoa + -juke $=$ "matar" + potat $=$ raiz verbal modal "querer", "poder" + jiapyt = marcador de repetição), "ele vai querer matar outra vez". A moderação referente ao resguardo do matador faz, portanto, com que um abate sempre esteja conectado a um outro.

Existem outras duas situações em que o caçador precisa ter atitudes moderadas: a chegada de um recém-nascido e a doença por parte de alguém com quem convive. Logo no parto são tomados diversos cuidados devido à intensa manifestação do piji do bebê. Seu cheiro contagia as pessoas com as quais ele vive, e os contagia com diferentes intensidades, sendo a mãe a mais afetada nesse momento. A circulação dela, mesmo pela aldeia, ficará bastante restrita durante sobretudo o primeiro ciclo lunar, dada a sua vulnerabilidade compartilhada com o bebê. O mesmo acontece com o pai, mas por apenas alguns dias. Mãe, pai e outros que convivem com o bebê não farão grandes esforços físicos, não andarão demais, evitarão atos que remetam a atitudes violentas. O piji mais intenso de uma criança não se 
arrefece tão cedo. Ele durará até quase a puberdade, diminuindo conforme seu crescimento avança. O pai deverá ficar sem caçar por algum tempo, e dependerá de receber carne de caça de outros homens, preferencialmente homens mais distantes, de aldeias vizinhas. A volta do pai à atividade de caçador vai acontecendo paulatinamente, restrita a caças mais específicas, como galináceos e roedores, e só bem depois poderá voltar a matar macacos, em seguida, caças terrestres grandes e, por fim, onças.

As doenças levam a todas essas mesmas restrições de atividades rotineiras, de andanças e a precauções na caçada, variando de acordo com a proximidade com a pessoa, como no caso de o caçador ser o pai do doente; com sua maturidade, sendo crianças e velhos menos fortes que jovens e adultos de meia-idade; e com o tipo e a intensidade da doença. As pessoas se encontram debilitadas em maior ou menor intensidade graças ao nascimento de uma criança, ao adoecimento de uma pessoa, à menstruação e à estreia de um matador. Elas se tornam mais py, "moles", dabekeri, "não fortes", e dijewori, "não dispostas". Sua -'ã , "alma", "princípio vital", está mais sujeita a deambular fora do corpo, o que pode ser perigoso, caso não retorne logo. O fato de as pessoas compartilharem piji faz com que elas também dividam essas características corporais. Elas se encontram mais vulneráveis a ações maléficas de todo tipo de seres, incluindo as das caças. Impõem-se restrições fortíssimas à vida do caçador. Matar caça pode ser extremamente arriscado, e é o principal motivo de vingança de animais da mesma espécie. E o principal remédio para evitar esse risco é a moderação.

Como foi visto, o piji é, portanto, uma categoria balizadora das relações com as caças. É por meio do piji que se justifica panem. Mas, também, o piji é central nas relações diretas com o alimento processado, sejam as carnes ou os vegetais. Querer comer e querer matar, assim como outras ânsias, não são vistos aqui como desejos abstratos, referidos a dimensões psicológicas. Tal como proposto por Peter Gow (1989:568), inevitavelmente desejos ligam pessoas a outras pessoas. São sistematicamente conectados a certas relações e, assim, permitem que identifiquemos os motivos e as consequências de se colocar em prática uma vontade. Com isso, estamos diante de questões importantes no pensamento ameríndio. Conter exageros não é simplesmente evitar riscos para si e para os seus, mas sim "riscos para os outros" (LéviStrauss 2008 [1968]:455), sendo parte de uma ética do decoro e da moderação (:459-460; Gallois 1988:213-217; Sztutman 2009:299).

E mais. Abster-se de matar demonstra como a vontade de cuidar subjaz à vontade de matar. Como demonstrou Dominique Tilkin Gallois para os Wajãpi, os resguardos e outros procedimentos relacionados a eles, como as restrições alimentares, " [...] não se constituem apenas em práticas defensivas, 
mas se configuram muitas vezes como tática de agressão. [...] De acordo com P. Grenand, 'são vistas mais como técnicas de luta do que como privações'" (1982:236; 1988:213).

Eu diria, no caso dos Zo'é, que os resguardos não são apenas momentos de cuidado e proibições, pois abster-se devidamente dá ao caçador uma potência para matar novamente quando da saída do período de reclusão, a moderação sendo, portanto, também prospectiva. Acontece que, se nos momentos de resguardo elencados acima, o caçador está impregnado de piji, e pode preferir se afastar das caças em troca de proteção, isto não quer dizer que ele tenha panem. O decoro instaura uma possibilidade e não uma certeza (cf. DaMatta 1967:73; Clastres 1995 [1972] :207; Garcia 2012:39-40; Almeida 2013:15). Como afirmam os Zo'é, somente se constatará panem quando o caçador de fato voltar a caçar: caso não encontre caça e, impreterivelmente, se as encontrar, flechar, mas não matar.

\section{Não matar: uma questão de gênero}

Mulheres jovens sem filhos, ou mesmo maduras cujos filhos já são relativamente grandes, podem ser parceiras preferenciais para acompanhar seus maridos caçadores (cf. Braga 2015:281; 2017:167-172). Elas ajudam na caçada. Podem levar os instrumentos utilizados, como arco e flechas, e carregar a caça abatida até a aldeia. Ficam junto do homem, em esperas. Porém, diferentemente deles, no'ãj, "elas não imitam" os sons das caças no intuito de enganá-las; não gritam para amedrontá-las e paralisá-las; e não ajudam nos cercos correndo atrás dos animais. Elas não contribuem diretamente com o abate da caça na floresta. Mulheres são consideradas como dabekeri, "não fortes" o suficiente para esticar a corda do arco; como dahari, que "não sabe correr rápido"; elas sesein kinean, "cansam rápido" quando é preciso subir as serras correndo atrás das caças. Mesmo seguindo seus maridos, afirmam-me que - diferentemente de outras mulheres indígenas (ver, por exemplo, T. S. Lima 1996:22; Garcia 2010:321-332) - kujã dohoj mo'ereket, "mulher não vai obter caça". Dizem nunca haver existido mulheres que caçavam. Elas não se dispõem a matar. Não matar, portanto, faz parte de condições normativas, aquilo que se espera de uma mulher no âmbito da caçada. Tanto homens quanto as próprias mulheres justificam o fato de elas não matarem caça em razão dessas (in)disposições corporais específicas. E isto tem consequências para panem. 
Certa vez conversei com uma importante mulher que me listou aqueles que eram bons caçadores e, também, os homens panem. Mencionou na segunda lista um de seus três maridos, que estava na rede ao lado. Indiscretamente, perguntei a ela por que ele não sabia caçar, e me respondeu: "Porqueeeee... [risos]. [...] Ele não obtém caça! Por isso, [é] tal como mulher. Isso, como mulher. [...] Ele não sabe trabalhar com procurar caça. Trabalhar com procurar caça [é] o mesmo que matar caça. [É] matar as caças". A condição de homem panem foi posta por ela em comparação com a condição de mulher enquanto alguém que não obtém caça, que pode ser sintetizada na seguinte correlação: Matar : Não matar :: Homem : Mulher :: Matador : Panem.

Não há na língua zo'é um termo específico para o verbo caçar. Eles utilizam predominantemente a expressão mo'ereke (mo'e = "coisa", "caça" + -eke = "procurar", "obter"), "procurar coisa". ${ }^{6}$ A partícula -eke(t) é utilizada nos mais diversos contextos, e pode receber a especificação daquilo que se procura, como em kwatareke, "procurar coatá", "caçar coatá", nareke, "procurar castanha", "coletar castanha" (Bertholletia excelsa), akuhaket, "eu procuro saber", "eu aprendo". Contudo, ainda que o termo mo'e possa ser usado, por exemplo, para se referir à coleta de castanha, este tipo de uso mais abrangente é raro, isto é, a expressão mo'ereke corriqueiramente se refere a caçar. Tendo isto em vista, noto que -eke(t) no âmbito da caçada indica uma circunscrição de gênero, se assim se pode dizer. Pois ainda que as mulheres sigam seus esposos para aquilo que entenderíamos como uma ida para a caçada, como visto acima, são apenas os homens que "obtêm" caça, porque são eles que -juke, "matam". Assim, dizer kujã dohoj mo'ereke é, a meu ver, justamente dizer que elas não vão de fato para matar.

"Nomo'erekej. A'e kujã rupijet!", "ele não obtém caça. Por isso, [é] como mulher". Como argumenta Marilyn Strathern, uma vez que estamos diante de um modo "como os sexos são pensados e como as qualidades sexuais vêm a ser aplicadas a outras formulações" (2014 [1980]:57), pode-se entender panem mediante uma perspectiva de gênero. A autora também ressalta que gênero não é um reflexo da diferença sexual apreendida por meio de uma compilação de traços referentes aos sexos: "Homens e mulheres são fontes de metáforas sobre masculinidade e feminilidade, mas tanto na combinação quanto na separação [entre os sexos], e isto eu considero como a 'relação' mais interessante entre eles (2001:266, tradução própria).

A proposição zo'é acima se soma a outras interações de "mesmo sexo" (Strathern 2001:266) - decorrentes da aplicação da garra do gavião-real por caçadores experientes em jovens caçadores em potencial; da distribuição da carne de anta pelo pai ou irmão do matador estreante etc. - e de "sexo 
cruzado" (Strathern 2001:266) - fruto do potencial de contágio do piji de uma mulher grávida, menstruada ou puérpera; da evitação de determinadas carnes por meninos pequenos, ao contrário das meninas, para não terem panem; da escarificação quando do abate de anta, feita por uma irmã, e da aplicação do colírio de olho de gavião-real por uma mulher casável; da proteção propiciada pela mãe ou uma irmã nas ações onça e cobra panem; do acompanhamento preferencial à caçada pela(s) esposa(s) etc. São interações acontecidas em contextos de propiciação de abates e/ou da moderação na caçada, das causas diretas de panem, mas também no âmbito normativo. Tal proposição afirma que não matar figura dentro de um quadro de correlações que envolvem os âmbitos da caçada e o das diferenças corporais e comportamentais esperadas. Características de mulheres e homens são cruzadas para se destacar uma diferença entre os sexos e, por sua vez, também entre os homens. E não só. Panem parece ser uma condição exclusiva dos homens - em se tratando da caçada, como já ressaltei. É do homem que se espera que mate caça. Mas se não matar aproxima determinados homens sob a mesma rubrica panem, é preciso matizar as diferenças entre eles.

\section{Pierre Clastres revisitado}

O viés de gênero de "panema" aparece explicitamente desde os primeiros trabalhos que trataram direta ou indiretamente do assunto. Eduardo Galvão (1951:223) apresenta as implicações das relações dos caçadores com as mulheres, atentando para os efeitos contagiosos da gravidez e do sangue menstrual. Décadas depois, tais efeitos viriam a ser ressaltados por Lúcia M. M. Andrade (1992:215) como passíveis de assumir um caráter transgressor, quando mulheres usavam essas potências contra os homens entre os Akuawa-Asurini. ${ }^{7}$

Na obra de Florestan Fernandes (1963 [1949]; 2003 [1952]), aparece a relação direta de panema com a sexualidade. Segundo o autor, panema acontecia no âmbito da guerra entre os Tupinambá. O termo designava o "ruim, mau, imprestável" (2003 [1952]:545). Um homem panema era também mébek, "mole", homens com os quais uma mãe não deixaria sua filha se casar (:257). E ainda mais:

O indivíduo que malograsse não só levaria uma vida miserável, com sérias dificuldades para obter companheira regular e merecer consideração dos outros, mas ainda seria excluído da sociedade sobrenatural [...]. O "covarde" ou "efeminado" ocupava, na sociedade Tupinambá, uma situação de proscrito e indesejável [...] (1963 [1949]:298). 
Vemos que panema aparecia como uma condicionante no modo de existir de determinados homens, e que isto tinha consequências diretas no seu destino post-mortem, questão que seguiu sendo fundamental para a tupinologia (ver, por exemplo, Clastres 1995 [1972]; Viveiros de Castro 1986; Gallois 1988; Andrade 1992; Garcia 2010; Sztutman 2012).

Foi com Pierre Clastres que a relação entre panema e sexualidade foi tratada em minúcia. O autor afirmou que, para os Aché, "todo espaço simbólico da masculinidade desdobra-se no ato do [...] flechar" (1995 [1972]:204); o arco e o cesto são um "resumo de dois 'estilos' de existência tanto opostos como cuidadosamente separados" (2003 [1974]:123); e um homem sem arco "não é mais um caçador, [...] não é mais nada" (1995 [1972]:208-209). Clastres discorreu sobre dois casos - enquanto duas opções - de homens panema entre os Aché: Krembegi, destro com o cesto tal como uma mulher, era um "pederasta", feliz com sua situação, enquanto Chachubutawachugi, ao não saber carregar o cesto, descontente por isso, era muitas vezes visto como um "palhaço" - estes termos estão a cargo do próprio autor (:211). A latência da imbricação entre panema e sexualidade tinha consequências drásticas no destino dos dois homens em questão. Tanto Krembegi quanto Chachubutawachugi estavam em um lugar "a meio caminho, [que] não existe" (:212). A condição de panema de Krembegi oferecia a ele a homossexualidade enquanto uma quase feminilidade. Mesmo aceitando o cesto, ele não era, no limite, uma mulher. "No limite", no caso, quer dizer uma mulher casável. Somente mantinha relações incestuosas com seus irmãos, ferindo a reciprocidade descrita pelo autor como um princípio de humanidade (:214-215). Por sua vez, ao não aceitar condição similar à de Krembegi, Chachubutawachugi não deixava de contrariar a reciprocidade, pois, como não matava ou, mais precisamente, não portava um arco para matar caças significativas (:212), quebrava os circuitos de troca de carne de caça tão importantes para os Aché.

À exceção de Andrade, trabalho bem mais recente, os outros autores citados acima não adotaram a noção de gênero como ferramenta analítica para realizar suas descrições. Todavia, a detecção feita por DaMatta (1967:7) de que panema pode acontecer durante algum tempo, mas também se tornar algo constante na existência de uma pessoa, somada à atenção de Fernandes para com a condição sexual de um homem panema como determinante para seu destino post-mortem e, por sua vez, ao modo como Clastres descreve as implicações da sexualidade na humanidade dos homens panema, abriram-me veredas metodológicas para encarar os imperativos etnográficos provenientes do trabalho com os Zo'é. Em primeiro lugar, perceber que é inevitável compreender panem estando alheio a diferentes aspectos de gênero e, 
por sua vez, em que termos panem pode acontecer como determinante do modo de existir de um homem. E, ainda, um último procedimento de análise presente em Clastres - e não em Galvão, DaMatta ou Fernandes -, que é a necessidade de multiplicar as análises de casos de homens panem para se apreenderem as diferenças entre eles. Apropriando-me do método descritivo de Clastres, menos do que tentar entender panem como um problema de (não) humanidade, observemos essas diferenças. ${ }^{8}$

\section{Muitos homens panem}

Se nas situações de moderação e consequente afastamento das caças, em que se escolhe não matar para cuidar dos outros, potenciais caçadores não são qualificados como panem, em outras situações, o são. Gostaria de atentar, de imediato, para o fato de que a quantidade de homens qualificados como panem - por outras pessoas e/ou por si mesmos - chama a atenção. A seguir, discorro sobre uma série de casos nos quais a qualificação como panem se dá justamente porque a relação de afastamento de determinada(s) caça(s) perdura, ou seja, nos termos de DaMatta (1967:73), não se trata neste caso de uma possibilidade, mas de uma certeza. ${ }^{9}$

É preciso considerar uma modulação de maneiras de existir enquanto homem panem (cf. Braga 2017:174-179). Há homens (P1, P2 e P3) ${ }^{10}$ de diferentes idades (46, 23 e 15 anos, respectivamente) que são considerados bastante ijewot, "dispostos" e bons caçadores. Mas que têm panem em relação a um tipo de caça em especial: matam de tudo, à exceção de anta. P4 (29) já matou caças variadas, incluindo anta. Mas nunca mata com frequência. Por sua vez, P5 (19) mata com frequência, mas apenas um mesmo tipo de caça, como determinadas aves, caçadas normalmente em tocaia.

Outros exemplos de panem referem-se àqueles homens que já mataram alguma caça no passado, mas que efetivamente hoje não matam mais. P6 (31) se dispõe a ir sozinho caçar, mas não consegue matar, mesmo ficando em tocaias. P7 (32) nunca vai sozinho, mas se dispõe a ir junto de outros caçadores. Ajuda em cercos contra caças terrestres e arborícolas. Fica dentro de tocaia com seu filho aprendiz, caçador promissor, para protegê-lo contra onças. Porém, também nunca mata. E P8 (30) é lembrado por ter um corpo tarak, "duro", atributo esperado para um bom caçador. Sempre carrega arco e flechas, mas sequer se dispõe a ir caçar, nem mesmo ir para tocaias; o arco e as flechas são para se defender das onças.

Entre os que não matam, existem aqueles que nunca mataram. Mesmo assim, P9 (15) se dispõe a acompanhar seu irmão um pouco mais velho, 
grande caçador. Diz-se de P10 (26) que dokuhaj mo'ereket, "ele não sabe obter caça". Ele não fica em esperas. Mas vai junto de seu irmão mais velho. Ele leva arco, mas não mata. Muito disposto, é exímio coletor. Por mais que não mate, ajuda pegando macacos que possam ter ficado enroscados nas copas das árvores. Dentre os que nunca mataram, há também os que não vão à caçada, mas que, contudo, são dispostos à realização de outras tarefas (P11, P12 e P13). Homens mais maduros (dois com 40 e um com 35 anos) pescam com frequência, esforçam-se muito no cultivo e no roçado, na coleta e na produção de farinha. Sabem fazer flechas, que são doadas para os filhos ou usadas por eles mesmos para se defenderem de onças. Dois deles vivem com bons caçadores, então têm carne de caça garantida. O terceiro usa a produção de farinha como forma de apoio a homens de aldeias vizinhas, uma vez que é o único homem adulto de seu agrupamento.

Por fim, entre os que nunca mataram, dois homens são referidos como dijewori, "não dispostos". P14 (13) nunca matou nada, nem mesmo passarinhos durante a infância. Não porta arco, nem sabe fazer flechas. Diferentemente dos matadores e dos outros homens panem descritos acima, não toma a bebida fermentada durante as grandes festas de sepy, algo que exige dos homens técnicas corporais bastante difíceis para se vomitar a bebida, uma exigência da festa. É o mesmo caso de P15 (22). Todavia, este é um homem com capacidades ímpares, como ter fluência na língua dos Tiriyó, povo indígena vizinho, e ter reconhecidamente a melhor desenvoltura entre todos os Zo'é para falar português.

Assim, temos: grandes caçadores e que mesmo assim têm panem; homens panem que matam, mas não com frequência; homens panem que matam, mas não caças variadas; homens panem que já mataram, mas agora não matam mais nada; homens panem que nunca mataram, mas se dispõem a ir para a caçada; e homens panem que nunca mataram e, de fato, sequer se dispõem a caçar. Strathern (2014 [1980]:65) lembra como as oposições de gênero são mobilizadas no âmbito do fracasso em Hagen: homens que fracassam podem ser tachados de mulheres, e mulheres que têm sucesso, como homens. Poderíamos entender todas essas situações descritas acima como uma mesma forma de fracassar?

\section{Contra a contrapartida}

Gostaria de me aproximar mais uma vez da etnografia de Clastres. Em determinado momento de sua narrativa, o autor assume o lugar de um Aché, mais precisamente, de um homem panema. E se pergunta: “Mas se 
eu estou pane, que contrapartida poderia oferecer, com que anularia o dom recebido? Não se pode receber sem dar, não se pode ao mesmo tempo estar pane e respeitar a regra de reciprocidade" (1995 [1972]:216).

Tomemos a retórica da necessidade de contrapartida como mote de um movimento que me permitirá fazer um exercício de especulação, aproximações desautorizadas pelos Zo'é. Estes nunca me expressaram diretamente qualquer tipo de compensação ao fato de alguém ter panem, como: "ele não caça, mas empenha-se muito no cultivo e no roçado". Entretanto, assumindo o lugar de um homem panem, poder-se-ia perguntar: "se não mato caça, o que posso oferecer como contrapartida?".

P12 (35), por exemplo, não caça e nunca caçou. Mas é reconhecido por sua grande disposição para outras atividades, como pesca, coleta, cultivo, roçado e produção de farinha de mandioca. Ele oferece seus préstimos para ajudar outras famílias quando se trata de produção em massa. O apreço dos Zo'é pelos derivados de mandioca é enorme - como está expresso no peju para atrair anta, visto acima. O consumo é diário, em praticamente todas as refeições. É extremamente indesejável comer carne sem farinha ou outros derivados de mandioca, algo que gera ânsia de vômito e, por isso, é preferível se passar fome. Além disso, não é bom comer refeições com carne repetidas vezes, assim, elas são intercaladas com mingaus de leite de castanha ou vinho de açaí (Euterpe sp.), por exemplo, ambos comidos com farinha. Não revezar pode deixar a barriga tarak, "dura", o que dificulta a evacuação, gerando dores terríveis. Nesse sentido, que lugares habitam homens panem altamente produtivos nessas outras atividades que não a caçada? Os Zo'é afirmam explicitamente que nokonani ise temi' $u$, "de forma alguma se troca comida". Mais exatamente estão dizendo que não há troca de comida por comida, não se troca carne por carne, mingau por carne, carne por farinha, mas é possível, e muito comum, que se troque carne ou farinha por parceria. Mais do que uma dinâmica de reciprocidade, este tipo de partilha parece enfatizar um acúmulo de relações: não só se dá algo em troca, mas sim, uma pessoa está junto de outra, participa-se de uma outra pessoa, como enfatizei alhures (cf. Braga 2017:28, 147, 158, 175, 182, 197, 205-206).

O fato de P1 (46) ter panem com anta pouco parece acarretar algum prejuízo em sua vida, inclusive em seu histórico como caçador, uma vez que sempre matou outros animais. Homem mais velho, continua indo caçar. Coleta, pesca, produz farinha e abre roças novas. É um ijet, chefe de grupo local, além de um dos principais conhecedores dos saberes dos antigos. Por outro lado, há um exemplo de homem panem chefe de grupo local que realmente não caça. É o caso de P10 (26). Como vimos, ele nunca matou. Nunca vai caçar sozinho, apenas acompanha seu irmão mais velho. 
Mesmo assim, tal como o primogênito caçador, é ijet do seu grupo. Havt (2001:188; cf. também Gallois 2015:294) destaca que é normalmente entre os ijet de grupo local que se destacam aqueles que têm iy, atributos de lideranças, definidos por três critérios básicos: conhecer os saberes referidos aos antigos, conhecer as relações de troca acumuladas entre os grupos e saber circular conhecimentos e distribuir adequadamente alimentos e bens de maneira geral. Obviamente, é a combinação entre eles que define a maior ou menor incumbência de um chefe. A autora (:189; cf. também Ribeiro 2020:80, 251-255, 311) também já destacara outra característica importante dos iy, sua iniciativa na abertura de novos caminhos de caçada, de novas roças, de novas aldeias, pioneirismo que "[...] aponta para o exercício da liderança entre os Zo'e como ações que são seguidas enquanto exemplos, iniciativas consideradas bem sucedidas que são atualizadas por outras ações" (:189). ${ }^{11}$

Mesmo tendo panem, e nunca tendo matado caça, P15 (22) e P11 (40) são exemplares em outras situações. Em 2010, os Zo'é tomaram a iniciativa de romper suas relações com a administração local da Funai, saindo de sua Terra Indígena em busca de uma aproximação com não indígenas e com os Tiriyó (cf. Gallois 2015; Ribeiro 2020). P15, à época com 19 anos, protagonizou episódios importantes nesse processo, dada, dentre outras coisas, a sua maior capacidade de falar português e tiriyó em relação aos líderes que tinham tomado tal iniciativa. Desde então, P15 passou a ser reconhecido como um homem que ika iy, no caso, tem boa capacidade de comunicação e conhecimentos de liderança diplomática. Já P11 - o caso de marido desprestigiado pela mulher, citado acima - em 2012 tomou a iniciativa da abertura do caminho e das aldeias no sentido sul do rio Erepecuru. $\mathrm{Na}$ sequência, outros ijet próximos a ele, incluindo alguns dos jovens iy que mais têm se destacado atualmente (cf. Gallois 2015), seguiram-no, abrindo suas próprias aldeias no caminho. Por isso, P11 é considerado uma referência na ocupação dessa região. Ambas as situações fazem parte de um processo histórico contemporâneo vivido pelos Zo'é, caracterizado pela expansão territorial e pela ampliação de alianças políticas com novos atores indígenas e não indígenas após os episódios de rompimento com a Funai referidos acima. Eles estão mantendo formas anteriores de relações entre os chefes e seus grupos, como a divisão em pequenos grupos e as largas possibilidades de rearranjos entre eles atualizando parcerias. Contudo, a ocupação dos limites da Terra Indígena, a abertura de aldeias nas margens de grandes rios, o aprendizado do uso de canoas e motores, o aumento do consumo de grandes peixes e novas alianças para obtenção de conhecimento e recursos materiais e financeiros são uma novidade muito valorizada por todos. 
Vê-se, por essa breve descrição, que as vidas de homens panem, guardadas as diferenças entre eles, não se reduzem ao fato de não matarem, isto é, de terem panem. Demonstrei como eles também têm disposições para diferentes atividades e outras capacidades extremamente valorizadas. É justamente a produção de corpos dispostos para tais atividades que aproxima positivamente homens (panem) e mulheres, uma vez que são disposições também produzidas nos corpos destas: disposição para a pesca, para o cultivo, para o roçado, para o processamento da mandioca etc. E não só, pois as competências enquanto ijet e iy também são atribuídas às mulheres, podendo ser reconhecidas como donas de aldeias e roças e como referências nos conhecimentos dos antigos e no histórico de relações entre os grupos, entre outros âmbitos do conhecimento.

Dessa feita, a necessidade de contrapartida associada à condição de ter panem deve ser relativizada. Nossas conclusões acima divergem analiticamente das de Clastres em relação aos Aché. Seja porque os Zo'é não são os Aché, ou porque talvez Clastres tenha cometido um equívoco ao hipervalorizar a reciprocidade a ponto de afirmar que ela engloba a caçada em si e/ou qualquer outro valor entre os Aché, ressalto uma diferença metodológica. Em sua etnografia, Clastres terminou por reduzir os dois casos concretos a um mesmo "movimento lógico" (:213), baseando-se em uma centralidade explicativa da reciprocidade. ${ }^{12}$ Contudo, lembro que, ainda em suas Crônicas, o autor fez pequenas mas importantes ponderações sobre as situações de Krembegi e Chachubutawachugi. Krembegi estava "à vontade" (Clastres 1995 [1972]:210): "De manhã, ele se vai em companhia das [mulheres] buscar larvas, frutos, palmito. Na volta, sua cesta não está menos carregada que a de suas companheiras" (:210), ênfases minhas). Já Chachubutawachugi, homem sem arco por condição, "continuava contudo a caçar os quatis à unha e a perseguir os tatus em sua toca" (:210). E completa: "[O]s inocentes caprichos de Chachubutawachugi são compensados por sua atividade, certamente reduzida, mas nada negligenciável, de caçador de quatis e tatus" (:212, ênfases minhas). A descrição da diferença entre Krembegi e Chuchabutawachugi e essas ponderações sobre suas competências, ainda que tivessem panema, permitiram-me atentar para o imperativo de compreender os diferentes modos de existir enquanto alguém que tem panem. 


\section{Relação de relações}

Vimos a importância do piji como uma categoria empírica que evidencia uma lógica das qualidades sensíveis, característica, por exemplo, da culinária, dos resguardos e, em especial, da caçada, explicativa de panem. Em um segundo nível, na medida em "que conecta pessoas entre si, e pessoas e animais" (Almeida 2013:16), o corpo de um homem panem opera como mediador, engendrando o que Lévi-Strauss denomina uma "lógica das proposições" (2006 [1968]:171, 422-423). A oposição sensível entre "podre" e "aromático" nas preferências alimentares, por exemplo - relação entre termos -, deriva-se para a relação entre a conjunção estabelecida por pessoas que compartilham piji e a disjunção entre homem e caça(s) relação entre relações. Essa relação se explicita com base na moderação necessária aos desejos do matador em potencial e das pessoas com quem compartilha piji: evitar comer determinadas carnes para não ter panem com outras caças da mesma espécie; cuidar para não matar demais ou em momentos inoportunos, para não gerar retaliações dos animais; abster-se de matar por desejar matar novamente etc. Se, como argumentei, tais desejos ligam pessoas, panem somente faz sentido na medida em que se manifesta por meio de uma pessoa. Ao invés de uma "força [...] impessoal" (Galvão 1951:222), panem é a própria pessoa, justamente porque a pessoa panem é uma relação de relações.

Por sua vez, panem não só divide - disjunção - os homens entre matadores e não matadores, mas, quando essa oposição se correlaciona àquela entre homens e mulheres, ela contraefetua (cf. Viveiros de Castro 2002b) - por conjunção - a masculinidade como estado sexual unificado:

Resta acrescentar que um estado sexual unificado (mesmo sexo) é criado através da não marcação ou marcação do elemento exógeno (outro sexo) de uma relação sexual cruzada [...]. Isso cria as condições para encontrar a parte "perdida" de uma pessoa no sexo oposto (Strathern 2001:226, tradução própria).

Panem é a atualização de uma "virtualidade" (cf. Viveiros de Castro 1996:118; cf. também T. S. Lima 1996:37; Viveiros de Castro 2002b), no caso, da possibilidade de matar como algo exclusivo aos homens em detrimento das mulheres. Nesse sentido, para além de indicar uma feminilidade absolutamente determinante na existência de um homem - tal como Fernandes compreendeu a respeito dos Tupinambá e Clastres sobre os Aché - panem compõe a masculinidade juntamente com o sucesso na caçada e, por isso, não me parece haver entre os Zo'é a exigência de que tal relação seja, no limite, expurgada do convívio social. 
Enquanto uma relação de desencontro entre o caçador e a(s) caça(s), panem pode dar outras direções para as relações entre as pessoas e, de diferentes maneiras, condiciona a vida de um homem, mas não a determina totalmente. A comparação entre mulheres e homens panem marca o aspecto negativo da caçada, não marcando positividades em outros âmbitos de sua existência. ${ }^{13}$ Considerando a necessidade de contrapartida como artifício retórico-etnográfico, atentei que homens panem, em suas variantes, participam de uma série de outras relações que não dizem respeito de imediato à caçada, e desenvolvem saberes específicos muito valorizados, incluindo a competência para diversos tipos de liderança. Observando-se diferentes relações e o modo como elas se relacionam entre si, pode-se vislumbrar a implicação também de homens panem na produção de e diferenciação entre pessoas e entre coletivos (cf. Sztutman 2012) enquanto processo histórico vivido pelos Zo'é.

É evidente que há um juízo nas concepções dos Zo'é sobre as diferenças entre grandes caçadores e homens panem e entre diferentes casos de homens panem. A proliferação de exemplos de panem, apontando-nos para a análise das pequenas diferenças entre eles e para as relações nas quais participam, reconhece essas diferenças e a importância delas, algo já esboçado alhures (cf. Braga 2017:147-151, 163-164, 183). Por ora, busquei apontar que qualidades sensíveis permitem entender o modo como pessoas se compõem de relações. Resta ser possível reinventar nosso olhar para as diferenças entre as pessoas e, talvez, se acreditarmos que homens panem também podem ser exemplo daqueles que "encarnam os modos da mediação" (Lévi-Strauss 2004 [1964]:76), percebermos como "todas as condições [...] são positivas a seu modo" (:76). Estarmos atentos ao sentido que panema nos aguça segue sendo sempre a melhor opção.

Recebido em 05 de junho de 2020

Aprovado em 13 de março de 2021 
Leonardo Viana Braga é doutorando em Antropologia pelo Programa de Pós-Graduação em Antropologia Social da Universidade de São Paulo - PPGAS/ USP e assessor do Programa Zo'é do Instituto de Pesquisa e Formação Indígena - PZ/Iepé. Tem experiência em etnologia indígena e interesse nos seguintes temas: gênero e povos indígenas, modos de saber, formação de pesquisadores indígenas, gestão socioambiental, e políticas para povos indígenas isolados e de recente contato. Desde 2012 vem atuando como pesquisador junto aos Zo'é, e desde 2016 passou a fazer parte da equipe responsável pela elaboração e a implementação do Plano de Gestão Territorial e Ambiental da Terra Indígena Zo'é, publicado em 2019.

https://orcid.org/0000-0001-6332-5345

E-mail: leovianabraga@gmail.com

\section{Notas}

* Este artigo é fruto de quase nove anos de pesquisa sobre o tema e da contribuição de cerca de duas dezenas de colegas que leram e comentaram versões anteriores a esta. Agradeço a eles e aos pareceristas da revista por suas sugestões significativas à versão final do texto e, sobretudo, aos meus amigos e amigas zo'é por me receberem sempre tão bem e permitirem que eu conhecesse um pouco dos seus modos de vida. Todo e qualquer equívoco é de minha inteira responsabilidade.

1 Os Zo'é são cerca de 320 pessoas falantes de uma língua tupi-guarani. Eles vivem exclusivamente em sua Terra Indígena homônima, homologada em 2009, no noroeste do estado do Pará. Organizam-se em pequenos grupos locais dispersos por seu território - atualmente são quatro grupos subdivididos em 18 subgrupos. Trata-se de região de densa floresta amazônica, no interflúvio dos rios Erepecuru e Cuminapanema, onde praticam a pesca, a coleta, o cultivo e têm na caçada uma atividade extremamente importante para sua característica mobilidade territorial.

2 Há na etnologia trabalhos de síntese sobre panema escritos por Eduardo Galvão (1951) e Roberto DaMatta (1967). Em artigo mais recente, Mauro W. B Almeida retoma o conceito em uma análise teórica mais ampla, focada em "conflitos ontológicos" (2013). Penso que seria importante a realização de um balanço bibliográfico mais atualizado sobre panema, que levasse em consideração uma série de trabalhos dentro e fora da etnologia que se debruçaram sobre o tema, ainda que indiretamente. Dado que meu foco aqui é sobretudo etnográfico, pretendo me dedicar a essa revisão em outra ocasião.

3 Análogo ao que acontece, por exemplo, com os seus vizinhos quilombolas do Erepecuru (Sauma 2013:148, 162), com os Yanomami (Kopenawa \& Albert 2015 [2010]:474) e com os Karitiana (Vander Velden, 2011:71). Ver, ainda, Almeida (2013:15). 
4 Como será visto à frente, tanto na proteção contra predadores e agressores quanto na propiciação de abates e nas próprias causas de panem, muitas vezes são correlacionadas oposições de gênero e de parentesco. Algumas ações são indicadas ou restritas ao -tu, "pai" (F), -tamu, "avô" (FF e MF), ao -amu, "outro", "irmão" (B, FB, MB, FZS, FBS, MZS, MBS, FZSS, FBSS, ZB, BS, MZSS, MBSD, ZDS, ZBS, BDS, BSS), a -hy, "mãe" (M), -totu, "avó" (FM ou MM) ou -ridyt, "irmã" (Z, FZ, MZ, FZD, FBD, MZD, MBD, FZDD, FBDD, ZD, BD, D, MZDD, MBDD) de um homem potencial caçador. Por outro lado, não recomendadas ou prescritas a uma -amute, esposa em potencial, ou a homens com os quais ele convive e que não sejam seu(s) -tu (os Zo'é são poliândricos e por isso cada pessoa tem normalmente mais de um pai), -tamu ou - $a m u$, não existindo uma categoria própria que englobe aqueles outros homens.

5 Ressalto que não tenho a pretensão de, por meio do uso dessas expressões, propor qualquer tipo de revisão do perspectivismo, tal como foi feito, por exemplo, por Fernando Santos-Granero (2006; para uma contra crítica ao autor, ver T. S. Lima 2011:640; Cabral de Oliveira 2012:149-152).

6 Outra expressão utilizada é -bodyj, "fazer dispersar". Mas ela tem um uso mais restrito, sendo empregada para se referir à caçada de animais que andam em bando, como coatás e queixadas (para uma comparação, cf. Garcia 2010:319-338). Uma outra é -rõ, "esperar", atitude necessária especificamente em tocaias e mutás, voltadas sobretudo à captura de cotias, pacas, mutuns e tucanos. Apesar de a ideia de -wata, "andar", compor a estética da caçada, sendo muito bem vistos os homens e as mulheres que andam muito e vão longe, não creio que possa ser usada como sinônimo de caçar ou como eufemismo para matar, comum a outros povos (ver, por exemplo, Garcia 2010:269-314).

7 Ainda sobre leituras de gênero sobre panema, ver Maria Motta-Maués (1998) e Iraildes Caldas Torres (2011). Destaco em suas contribuições as relações entre alimentação e panema, entendidas por meio das diferenças de gênero (Motta-Maués 1998), e a forma como as relações que panema opera estão sujeitas a atualizações históricas (Torres 2011:108).

8 Antecipo-me aqui para tratar de uma questão ética da pesquisa. Visando não expor os homens qualificados como panem, o tema da ligação entre panema e sexualidade entre os Zo'é não será tratado diretamente neste artigo. Por ora, basta dizer que existem relacionamentos entre homens zo'é, e que envolvem tanto homens panem quanto os que não têm panem. O importante aqui é reafirmar que a condição de um homem panem não se reduz ao fato de ter panem, tampouco à sua sexualidade.

9 Não pude ir a fundo nas causas de panem nos casos específicos que serão elencados a seguir.

10 Também por motivos éticos, utilizarei a notação $\mathrm{P}=$ panem, justaposta à numeração que faz referência aos diferentes casos de homens qualificados como panem: P1, P2, P3, e assim por diante. Entre parênteses seguem as respectivas idades desses homens quando os dados foram produzidos. 
11 Para uma sistematização sobre ir à frente como modo de liderança, ver Renato Sztutman (2012).

12 O próprio Clastres (2004 [1980]) viria a criticar posteriormente um tipo de conclusão "troquista" (T. S. Lima, 2011:625; cf. também Soares-Pinto 2017:537, 544), que derivou a ênfase de sua análise para a guerra. Sobre a distinção entre panema e troca no que concerne à retribuição, ver Almeida (2013:21, nota 40).

13 Sobre a importância da oposição entre marcado e não marcado nos modos de classificação ameríndios, ver, por exemplo, Lévi-Strauss (2003 [1963]:214; 2006 [1968]:24-25, 35, 129, 223-224, 431, 449), Eduardo Viveiros de Castro (2002a) e Joana Cabral de Oliveira (2012:25, 34-35, 44, 77, 81). Especificamente sobre panema, para uma comparação com o caso Araweté, ver Camila de Caux, que destaca a negatividade de uma "relação de ausência" (2017:436-437, 443) e/ou uma "relação marcada pela disjunção" (:440) em diferentes âmbitos, incluindo o parentesco e a caçada. Por fim, ver Nicole Soares-Pinto (2017), que qualifica o incesto entre os Djeoromitxi ora como "uma não relação" (:536) - ressaltando sua face negativa, seguindo Anne-Cristine Taylor -, ora como "autorrelação" (:536-537) - atentando para sua face positiva, conforme Jadran Mimica - e, o que nos interessa aqui, afirmando que é possível que o incesto "esteja metaforizado no estado panema" (:536). 


\section{Referências bibliográficas}

ALMEIDA, Mauro W. B. 2013. "Caipora e outros conflitos ontológicos".R@URevista de Antropologia da UFSCar, São Carlos-SP, v. 5, n.1:07-28, jan.jun.

ANDRADE, Lúcia M. M. de. 1992. O Corpo e os Cosmos: relações de gênero e o sobrenatural entre os Asurini do Tocantins. Dissertação de Mestrado em Antropología Social, Universidade de São Paulo.

BELAUNDE, Elvira. 2006. "A força dos pensamentos, o fedor do sangue: hematologia e gênero na Amazônia". Revista de Antropologia (USP. Impresso), v. 49, n. 1:205-243.

BRAGA， Leonardo Viana. 2015. "Micropeças sobre gênero e caçada junto aos Zo'é". In: Denise F. Grupioni \& Lúcia M. M. Andrade (orgs.), Entre águas bravas e mansas. Índios e Quilombolas de Oriximiná. São Paulo: CPI-SP \& Iepé. pp. 272283.

. 2017. Pani'em. Um esboço sobre modos de saber entre os Zo'é. Dissertação de Mestrado em Antropologia Social, Universidade de São Paulo.

CABRAL DE OLIVEIRA, J. 2012. Entre plantas e palavras. Modos de constituição dos saberes entre os Wajápi (AP). Tese de Doutorado em Antropologia Social, Universidade de São Paulo.

CAUX, Camila de. 2017. "O solteiro, o porco inteiro, o caçador sem caça: o "um" entre os Araweté. Revista de Antropologia, v. 60, n. 2:436-459.

CLASTRES, Pierre. 1995 [1972]. Crônica dos índios Guayaki. O que sabem os Aché, caçadores nômades do Paraguai. Rio de Janeiro: Editora 34.
. 2003 [1974]. "O Arco e o Cesto". A sociedade contra o Estado, e outros ensaios. São Paulo: Cosac \& Naif. pp. 117-143.

. 2004 [1980]. "Arqueologia da violência: a guerra nas sociedades primitivas". Arqueologia da Violência. Pesquisas de antropologia política. São Paulo: Cosac \& Naif. pp. 229-270.

DAMATTA, Roberto. 1967. "La panema: un essai d'analyse structurale. L'Homme, tome 7, n. 3:5-24.

DESCOLA, Phillippe. 2001 [1996]. "Construyendo naturalezas: Ecologia simbólica y prática social". In: Philippe Descola \& Gísli Pálsson (coords.), Naturaleza y Sociedade. Pespectivas antropológicas. Ciudad de México: Siglo Veintiuno Editores. pp. 101-123.

. 2006 [1993]. As lanças do crepúsculo: relações jivaro na Alta Amazônia. São Paulo: Cosac \& Naify.

FERNANDES, Florestan. 1963 [1949]. A Organização social Tupinambá. 2. ed. revista e ampliada. Lisboa: Difusão Europeia do Livro. . 2006 [1952]. A função social da guerra na sociedade tupinambá. 3. ed. São Paulo: Editora Globo.

GALLOIS, Dominique Tilkin. 1988. O movimento na cosmologia Waiapi: criação, expansão e transformação do universo. Tese de Doutorado em Antropologia Social, Universidade de São Paulo. . 2015. "Alguns modos zo'é de fazer coletivos e lideranças". In: Denise F. Grupioni \& Lúcia M. M. Andrade (orgs.), Entre águas bravas e mansas. Índios e Quilombolas de Oriximiná. São Paulo: CPI-SP \& Iepé. pp. 285296. 
GALVÃO, Eduardo. 1951. "Panema. Uma crença do caboclo amazônico". Revista do Museu Paulista, n.s., v. $\mathrm{V}: 221-225$.

GARCIA, U. F. 2010. Karawara. A caça e o mundo dos Awa-Guajá. Tese de Doutorado em Antropologia Social, Universidade de São Paulo. . 2012. "O funeral do caçador: caça e perigo na Amazônia". Anuário Antropológico, v. II:33-55.

GOW, Peter. 1989. "The perverse child: desire in a native amazonian subsistence economy". Man, n.s., 24:567-582.

HAVT, N. B.2001. Representações do Ambiente e da Territorialidade entre os Zo'é/PA. Dissertação de Mestrado em Antropologia Social, Universidade de São Paulo.

KOPENAWA, Davi \& ALBERT, Bruce. 2015 [2010]. A queda do céu. Palavras de um xamã yanomami. São Paulo: Companhia das Letras.

KWON, Heonik. 1998. "The saddle and the sledge: hunting as comparative narrative in Siberia and beyond". The Journal of the Royal Anthropological Institute, v. 4, n. 1:115-127.

LÉVI-STRAUSS, Claude. 2004 [1964]. O cru e o cozido. Mitológicas I. São Paulo: Cosac Naify. 2005 [1967]. Do mel às cinzas. Mitológicas II. São Paulo: Cosac Naify. 2006 [1968]. Origem dos modos à mesa. Mitológicas III. São Paulo: Cosac Naify. 2008 [1962]. O pensamento selvagem. 9. ed. Campinas-SP: Papirus Editora.

LIMA, T. S. 1996. "O Dois e seu Múltiplo: Reflexões sobre o Perspectivismo em uma Cosmologia Tupi". Mana, v. 2, n. 2:21-47.
2011. "Por uma cartografia do poder e da diferença nas cosmopolíticas ameríndias". Revista de Antropologia, v. 54, n. 2:601-646.

MOTTA-MAUÉS, M. A. 1998. "'Lugar de mulher': representações sobre os sexos e práticas médicas na Amazônia (Itapuá/Pará). In: Paulo César Alves \& Maria Cecília S. Minayo (orgs.), Saúde e Doença: um olhar antropológico. 2. ed. Vol. 1. Rio de Janeiro: Fiocruz. pp. 113-125.

MONTOYA, Antonio Ruiz de. 2011 [1639]. Tesoro de la lengua guaraní. Asunción: Centro de Estudios Paraguayos "Antonio Guasch" CEPAG.

RIBEIRO, F. A. N. 2020. Encontros zo'é nas Guianas. Tese de Doutorado em Antropologia Social, Universidade de São Paulo.

SANTOS-GRANERO, Fernando. 2006. "Vitalidades sensuais: modos não corpóreos de sentir e conhecer na Amazônia". Revista de Antropologia (USP. Impresso), v. 49, n. 1:93-132.

SAUMA, Julia Frajtag. 2013. The Deep and the Erepecuru: Tracing transgressions in an Amazonian Quilombola territory. Thesis submitted for the degree of Doctor of Philosophy (PhD), University College London, Department of Anthropology.

SOARES-PINTO, Nicole. 2017. "'Pequeno manual para se casar e não morrer': o parentesco djeoromitxi. Mana, v. 23, n. 2:519-549.

STRATHERN, Marilyn. 2001. "SameSex and Cross-Sex Relations: Some Internal Comparisons". In: Thomas Gregor \& Donald Tuzin (eds.), Gender in Amazonia and Melanesia. An exploration of comparative method. Berkeley/Los Angeles/London: University of California Press. pp. 221-244. 
2014 [1980]. "Sem natureza, sem cultura: o caso Hagen". In: Marilyn Strathern; Iracema Dulley; Jamille Pinheiro Dias \& Luísa Valentini, O efeito etnográfico, e outros ensaios. São Paulo: Cosac Naif. pp. 23-75.

SZTUTMAN, Renato. 2009. "Ética e profética nas Mitológicas de LéviStrauss". Horizontes Antropológicos (UFRGS - Porto Alegre-RS), v. 15:293-319.

. 2012. O profeta e o principal: a ação política ameríndia e seus personagens. 1. ed. Vol. 1. São Paulo: Edusp.

TORRES, Iraildes Caldas. 2011. "Mulheres Pescadoras e a Ressignificação do Mito do Panema". In: Iraildes Caldas Torres \& Fabiane Vinente dos Santos (orgs.), Intersecção de Gênero na Amazônia. 1 ed. Vol. 1. Manaus: Editora da Universidade Federal do Amazonas, EDUA. pp. 108-117.

VANDER VELDEN, F. F. 2011. "Inveja do gado: o fazendeiro como figura de poder e desejo entre os Karitiana". Anuário Antropológico, v. 2010/1:5576.

VIVEIROS DE CASTRO, Eduardo. 1986. Araweté: os deuses canibais. Rio de Janeiro: Jorge Zahar/ANPOCS. . 1996. "Os pronomes cosmológicos e o perspectivismo ameríndio". Mana, 2 (2):115-144.

2002a. "Esboço de cosmologia yawalapíti". A inconstância da alma selvagem e outros ensaios". São Paulo: Cosac Naif. pp. 27-85.

. 2002b. "Atualização e contraefetuação do virtual: o processo do parentesco". In: Inconstância da alma selvagem. São Paulo: Cosac Naif. pp. 401-455.
WILLERSLEV, Rane. 2012. "Percepções da presa: caça, sedução e metamorfose entre os Yukaghirs da Sibéria". Anuário Antropológico, 2011-II:57-75. 


\section{PANEM. SOBRE SEU VIÉS DE GÊNERO ENTRE OS ZO'É}

\section{Resumo}

Esse artigo se insere no debate sobre panema, noção que caracteriza uma conhecida situação de insucesso na caçada. Entre os Zo'é, povo indígena da Amazônia brasileira, panema faz parte de uma lógica das qualidades sensíveis, uma vez que o corpo do homem panema é descrito como fétido, justificando o afastamento das caças. No primeiro momento do texto, demonstra-se como os aspectos olfativos conectam à caçada a diferentes âmbitos, tais como a culinária e os resguardos. É destacada a importância da moderação como uma potência para o sucesso no abate. Em um segundo momento, analisa-se a proposição de que o insucesso na caçada permite a comparação de homens panema com mulheres. Em se tratando de não matar caça, argumenta-se que o corpo panema é uma exclusividade dos homens em detrimento das mulheres. Por sua vez, propõe-se que a perspectiva de gênero combinada à atenção a diferentes casos de homens panema permite relativizar uma possível negatividade da existência dos mesmos, argumentando-se que sua vida não se reduz a tal condição. Com isso, pretende-se contribuir com o entendimento da noção de relação em etnologia, e, mais especificamente, de panema como um conceito de ampla circulação na Amazônia e além.

Palavras-chave: lógica das qualidades sensíveis; gênero; relação; panema; Zo'é.

\section{PANEM. ITS GENDER BIAS AMONG} THE ZO’É

\section{Abstratc}

This article concerns "panema", a notion that characterizes failure in hunting. Among the Zo'é, an Indigenous people of the Brazilian Amazon, "panema" is part of a logic of sensible qualities, since the body of a "panema" man is described as fetid, justifying his exclusion from the hunt. The first part of the article shows how the olfactory aspects of hunting connect it to different areas, such as culinary activity, the couvade and the seclusion of the killer. The importance of moderation for success in the kill is stressed. In the second part of the article, I analyze the proposition that failure in the hunt leads "panema" men to be compared to women. When it comes to not killing game, it is argued that the "panema" body is exclusive to men to the detriment of women. In turn, I propose that a focus on gender alongside an attention to different examples of "panema" men allows us to relativize a potential negativity of their existence, and to argue that their life is not reduced to their condition. I thus intend to contribute to an understanding of the notion of 'relation' in ethnology, and, more specifically, of "panema" as a concept with a wide circulation in the Amazon and beyond.

Keywords: logic of sensible qualities; gender; relationship; panema; Zo'é. 


\section{PANEM. SOBRE SU ENFOQUE DE GÉNERO ENTRE LOS ZO'É}

\section{Resumen}

Este artículo se incorpora al debate sobre "panema", una noción que caracteriza una conocida situación de fracaso en la cacería. Entre los Zo'é, pueblo indígena de la Amazonia brasileña, "panema" forma parte de la lógica de cualidades sensibles, ya que el cuerpo del hombre "panema" se describe como fétido ytiene como consecuencia el alejamiento de los animales de caza. En la primera parte del texto, se muestra cómo los aspectos olfativos asocian la caza a diferentes ámbitos, como la culinaria y el resguardo; se destaca, también, la importancia de la moderación como una potencia para el éxito en la matanza. En un segundo momento, se analiza la hipótesis de que no tener éxito en la caza posibilita la comparación de los hombres "panema" con las mujeres. En relación al hecho de no lograr matar un animal de caza, se argumenta que "el cuerpo panema"" es una exclusividad de los hombres en detrimento de las mujeres. A su vez, se plantea que la perspectiva de género aplicada a la observación de diferentes casos de hombres "panema" permite relativizar una posible negatividad de su existencia, argumentando que sus vidas no se reducen a dicha condición. Con ello, se pretende contribuir a la comprensión de la noción de relación en la etnología, y más concretamente, de "panema" como un concepto de amplia circulación en la Amazonia y en otras regiones.

Palabras clave: lógica de cualidades sensibles; género; relación; panema; Zo'é. 